\title{
Urbanidade e disciplinarização e o imigrante italiano nas relações sociais: o Método Facile*
}

\section{Rosa Lydia Teixeira Corrêa**}

\begin{abstract}
Já é muito conhecer a língua de um país, ou possuir informação sobre ela. Uma pessoa que se encontra nesta condição, tem maior probabilidade de conseguir um emprego bem remunerado.

Se, ao contrário, ignora a língua, deve submeter-se à ação de um intérprete, que traduzirá o que pensa, é um sujeito infeliz e que fará muito pouco (se não é um espírito inteligente), maldizerá o momento em que veio para a América.
\end{abstract}

Carlo Del Rosso

\section{RESUMO}

Este trabalho resulta de análise de textos que compõem o Método Facile, compreendendo-o como uma proposta educativa para imigrantes italianos no Brasil no início da república. Tal proposta se desenvolve por meio da possibilidade que tem o imigrante de aprender a língua portuguesa sem precisar de auxílio de professor, para o que esse método proporciona as devidas orientações. Ao mesmo tempo em que é permitido a esse imigrante a oportunidade de aprender a falar a língua portuguesa, são incutidas noções de civilidade, de cortesia, de abnegação com o trabalho, de devoção e de respeito a Deus. O Método Facile resulta de iniciativa da Sociedade Promotora da Imigração, tendo sido publicado em 1892.

Palavras chave: imigração, educação, língua portuguesa.

* Este artigo resulta de capítulo elaborado para a tese de doutorado defendida em abril de 2000, na Universidade de São Paulo, que trata da educação como estratégia de sobrevivência por parte de imigrantes italianos no Estado de São Paulo, particularmente em Campinas. A pesquisa contou com o apoio da CAPES.

** Doutora em História - PUC-Campinas. 


\begin{abstract}
This work results from the analysis of texts that compound the "Método Facile" which is understood as an educational proposition for Italian immigrants in Brazil in the beginning of the Republic. Such a proposition is developed by means of the possibility that the immigrant have to learn the Portuguese language without professor assistance for which this method provides right orientations. At the same time in that is allowed to this immigrant the opportunity of learn to talk the Portuguese language, it's inculcated to him notions of civility, of courtesy of abnegation to work, of devotion and respect to God. The "Método Facile" results from the initiative of the "Sociedade Promotora da Imigração" having been published in 1892. Key-words: immigration, education, Portuguese language.
\end{abstract}

\title{
A aprendizagem da língua como estratégia de sobrevivência
}

Ao tratar de uma proposta de convivência social diferenciada, este texto aborda uma forma de educação que também se diferencia devido à singularidade do conteúdo que contempla. Diz respeito ao conteúdo do "Método Facile" (método fácil em italiano), ${ }^{1}$ uma diretriz teórico-metodológica sobre o uso da língua portuguesa em solo brasileiro. O compêndio que compõe esse método está dividido em dez partes. ${ }^{2}$ Não foi organizado por imigrantes

1 Foi publicado no ano de 1892 pela Casa Editrice A. Bietre, respectivamente em Milão e Buenos Aires. Em Milão, no endereço Corso P. Romana, 86, e, em Buenos Aires, 631, Calle Moreno, 633.

2 A primeira parte contém seis exercícios com diálogos em português para memorização; a segunda está composta por vinte e seis capítulos; a terceira, organizada em vinte e seis capítulos, trata de aspectos da gramática portuguesa; a quarta, em vinte e dois capítulos, aborda palavras do vocabulário português; a quinta trata de terminologias comerciais; a sexta parte, da lei aprovada pelo ministro Francisco Glicério, que regula a imigração no Brasil; a sétima, da moeda utilizada no Brasil; a oitava trata das companhias de navegação que transportam imigrantes para o Brasil; a nona demonstra o regulamento brasileiro, quanto ao recebimento, abrigo e destino do imigrante; a décima e última parte faz uma descrição geral do Brasil e de seus Estados em particular. 
italianos que vieram para o Brasil, mas por um compatriota. ${ }^{3}$ As orientações gerais de estudo, bem como os conteúdos de caráter informativo, estão escritos em italiano. O manual resulta de uma iniciativa da Sociedade Promotora da Imigração. ${ }^{4}$ Não sabemos quem e tampouco quantos italianos fizeram uso dele. Entretanto, o que provocou seu estudo foi o fato de considerarmos os objetivos segundo os quais foi organizado: o ensino/aprendizagem/uso da língua portuguesa falada. Implicitamente, traz a intenção de fomentar no imigrante italiano uma atitude educativa autodidata, dada pela orientação metodológica criteriosa a partir da sua organização didática e pela preocupação com o tempo que o estudante/imigrante deveria dedicar a cada uma de suas partes a serem memorizadas.

O Método Facile comporta dois tipos de educação: a formal e a informal. Formal, enquanto organização didática e metodológica. Nesse sentido, embora assim o entendamos, não pode ser situado exclusivamente nos parâmetros de uma orientação educativa escolar, espaço supremo desse tipo de educação. Para BRANDÃO (1986), "o ensino formal é o momento em que a educação se sujeita à pedagogia (teoria da educação), cria situações próprias, para o seu exercício, produz os seus métodos, estabelece suas regras e tempos e constitui executores e especializados. É quando aparecem a escola,

3 O autor é o professor Carlo Del Rosso, Secretario do "Ofício de Informação do Governo do Brasil em Milão". Convém salientar que, já em 1886, o jornal Diário de Campinas divulgava, em sua edição de 20 de julho, "que por ordem do Ministro da Agricultura estava-se organizando um Guia do imigrante no Brasil", o qual seria impresso e divulgado na Europa. Dizia ainda que o livro teria todos os esclarecimentos oficiais necessários aos europeus que pretendessem emigrar. Esse mesmo jornal, em 20 de setembro de 1888, noticiou que "A Sociedade de Imigração, fundada em Juiz de Fora, mandou imprimir na Europa e estaria sendo distribuído largamente em diversos países europeus, um Guia do Imigrante, dando esclarecimento sobre a província de Minas para servirem a todos aqueles que procurassem essa província e sobre ela desejassem informações detalhadas." Acrescenta que "acompanharia o Guia um mapa da província de Minas, indicando as principais localidades, vias de transporte." O autor dedica essa obra ao Conselheiro Dr. Antônio da Silva Prado, que foi Ministro da Agricultura no Império.

4 Fundada em São Paulo, em meados de 1886, a Sociedade promotora da Imigração nasceu com o propósito de melhorar a imagem do Brasil na Europa, em virtude das propagandas negativas que vinham sendo divulgadas em relação às condições de vida e tratamento do imigrante. Encerrou suas atividades em 1895, já na República. Sua permanência durante o período inicial desse regime, é explicada pelo fato de que, embora tenha havido mudança de regime, a organização burocrática do império continuou a mesma. Por isso, essa sociedade continuou desenvolvendo suas atividades. Cf. HOLLOWAY, T. Imigrantes para o café: café sociedade em São Paulo 1886-1934. São Paulo: Paz e Terra, 1984. p. 64-65. 
o aluno e o professor."5 Assim, o guia de estudo traz uma dimensão de educação formal, justamente pelo fato de ser um método, pelas situações próprias que estabelece para procedimento de estudos, através de regras e tempo previamente estabelecidos para isso. Nesse sentido, não deixa de ser uma pedagogia, mesmo que não contenha pressupostos educativos claramente definidos, ou seja, não há fundamentos teóricos que expliquem, por exemplo, a pertinência da aprendizagem baseada na memorização a partir da repetição. Isso não significa, por outro lado, que tais princípios não possam ser abstraídos dessa proposta educativa. Falaremos deles mais adiante.

Entretanto, a educação não é formal, pois a presença do professor está somente nas entrelinhas, portanto, indiretamente; assim como não há, simultaneamente, a relação aluno/professor. Em contrapartida, sua informalidade, o que aqui nos interessa em particular, é proporcionada pela possibilidade que permitiria ao imigrante se apropriar de um conhecimento (da língua portuguesa) sem ter que ir a uma escola e, por isso, fazê-lo de maneira que seu tempo e afazeres cotidianos aprouvessem. Por essa razão, a educação se processaria de maneira assistemática, sem precisar da presença de um professor. Esse tipo de educação pode, ainda, ser entendido na perspectiva que nos orienta BRANDÃO (1986): "para aprender, para ensinar, para fazer, para ser ou para conviver." ${ }^{\circ}$ Assim, esse mesmo autor corrobora com a idéia de que não existe um único modelo de educação. ${ }^{7}$

Além de poder ser caracterizado como um compêndio de conteúdo aparentemente pragmático/utilitarista, é substancialmente revelador de uma proposta que pretende situar o imigrante no universo de relações que lhe estão dadas a priori, quais sejam: algumas possibilidades de trabalho e de sobrevivência, bem como a subserviência que essas relações acarretam. Nesse sentido, esse método se presta a dois objetivos: um pedagógico e outro ideológico.

Ao escrever, na introdução, Ai mei cari fratelli emigranti ${ }^{8}$ o professor Carlo Del Rosso conclama o italiano imigrante a ser laborioso, ganhar dinheiro, ficar rico e ser, ao lado disso, digno, honesto e honrado. Não sem antes dizer

5 BRANDÃO, C. R. O que é Educação. São Paulo: Brasiliense, 1986. p. 26.

6 Ibid., p. 7.

7 Ibid., p. 8.

8 Tradução do original em italiano: "Ao meu caro amigo emigrante". O texto contendo a mensagem está nas páginas 7, 8 e 9 do método. Cf. DEL ROSSO, C. Método Facile: teóricopratico per imparare senza maestro la língua portoghese. Manuale indispensabile per L'emigrante che si al Brasile. Buenos Aires: Casa Editriche A. Bietti, 1892. 
que "o vosso estandarte será sempre a bandeira da Itália expressada numa firme vontade de trabalhar contrariamente a uma vida sem sentido." A seguir, dedica grande parte dessa espécie de prefácio para alertar o imigrante sobre o fato de que "na América não se faz fortuna sem suor. Se acreditas que chegarás a um país e farás fácil riqueza, não te enganes, porque sofrerás dolorosa desilusão. $\mathrm{Na}$ América podes estar forte de corpo e de mente, de firme propósito e poderás gozar de uma condição profícua e laboriosa; mas o preguiçoso, o ignorante, o fraco só verá a miséria, a sepultura!" Através dessas passagens, o autor e idealizador ${ }^{9}$ deixa a nítida compreensão de que todas as condições de sucesso ou de insucesso que pudesse experimentar o imigrante no Brasil dependeriam exclusivamente dele. Deparamo-nos com uma concepção individualista de convivência e de sobrevivência social do imigrante em solo estrangeiro, para o que não concorreriam fatores externos dados pelas condições materiais de existência e, nem tão pouco, por relações adversas, ou mesmo de resistências que pudessem ser oriundas de grupos de brasileiros nos locais para os quais o imigrante se destinou ou foi destinado.

Isso nos permite refletir sobre o imigrante italiano que se deparou com situações adversas, que experimentou intempéries de diferentes naturezas e que servem para demonstrar a incoerência de compreensões deveras positivistas sobre essa questão. Vejamos, a exemplo, um trecho elucidativo de adversidade, narrado, dentre outros, pela imprensa de Campinas, através da passagem abaixo:

Informaram-nos que hontem estavam na estação de Valinhos uns $\underline{\text { dez }}$ imigrantes italianos recém-chegados, chorando com fome! Disseramnos que esses imigrantes tendo sido contratados para uma fazenda daquele bairro, sob condição de serem alimentados durante os primeiros seis meses, por conta do proprietário, cláusula que este depois não cumpriu. ${ }^{10}$

9 Tudo leva a crer que Rosso foi quem idealizou o método, pois é ele mesmo quem diz no prefácio de sua obra: "[...] como havia dito, este livro é fruto de meu ânimo para ser útil naquele distante e vasto país sul-americano que se chama Brasil. Aquela coisa na qual pensei naquele dia ao amanhecer quando era necessário viver no estrangeiro no meio daquela gente, a importância de conhecer a língua, seus usos e costumes, a lei e o modo de obter uma ocupação.” (p. 8)

10 Jornal Diário de Campinas, 24 dez. 1887, (AEL) Unicamp. Grifos nossos. 
O professor prossegue com sua mensagem doutrinária, enfatizando que "a lei não protege aqueles que enveredam por caminhos tortuosos, mas os que mantém reta consciência". Chama a atenção para que o imigrante, quando "sentir-se agredido, solicitar sempre a proteção da lei, invocando a autoridade, porém, em momento algum, deve adotar atitudes de represálias". Do contrário, "restará sempre o dano do forasteiro e, de outro modo, do italiano que, fora da Pátria, goza de uma fama pouco lisonjeira, fama que em nada dignifica nossa nação." 11 Diante disso, demonstra desconhecer que a lei nem sempre é justa como se propõe a ser. A carta abaixo soa bastante factual em relação a essa questão, na qual a própria vítima, um italiano, denuncia, através da imprensa, a arbitrariedade sofrida:

O Correio e Diário de Campinas noticiaram que fora preso o italiano Miguel Pinetti por ter provocado a patrulha e acrescentaram que a prisão fora efetuada por um soldado e quatro paisanas que prenderam o abaixo assignado e deram essa informação à polícia effectivamente; mas ela foi completamente falsa.

Eu não provoquei patrulha alguma, pois diante de mim nessa ocasião só havia um soldado desarmado; e a prisão foi efetuada por dois sujeitos, vagabundos de marca garantida, merecedores de irem purgar a sua vadiação no exército ou sob o calabrote da marinha. É verdade que desapareceram $40 \$ 000$ e o meu relógio depois que fui preso. Parece que o sistema é prender gente para depenar. Deixo aqui a exposição do facto, para que o delegado de polícia fique sabendo como fui preso e quem foi que effectuou a prisão. Pode S. S. verificar a verdade, se quizer.

Campinas, 30 de julho de 1888 .

Miguel Pinetti ${ }^{12}$

O autor finaliza o prefácio se reportando ao que é fundamental em sua obra, o conhecimento da língua e, nesse sentido, mais uma vez orienta o imigrante sobre o fato de que esse conhecimento não só proporciona saber sobre os costumes, as leis e preços de mercado de um país, mas deve significar para ele que é portador de um status e, ao mesmo tempo, a certeza da razão

11 DEL ROSSO, op. cit., p. 8

12 Jornal Diário de Campinas, 31 jul. 1888, (AEL) Unicamp. 
pela qual veio para a América. Isso significa, também, "não se furtar a um amanhã lisonjeiro".

Na verdade, o que realiza nessa primeira etapa do livro se situa no âmbito daquilo que entendemos como tentativa de realizar, antes de tudo, uma espécie de domesticação através da aprendizagem e, por isso, disciplinar o estrangeiro nas relações a serem travadas nos espaços de convivência social em solo brasileiro. Assim, não só nesse preâmbulo, mas também em toda sua obra, o autor expressa nitidamente a intenção de exercer, tanto através das orientações para o aprendizado da língua quanto do conteúdo utilizado, um poder que é "simbólico como poder de constituir o dado pela enunciação, de fazer ver e fazer crer, de confirmar ou de transformar a visão de mundo e, deste modo, a ação sobre o mundo; [...] poder quase mágico que permite obter o equivalente daquilo que é obtido pela força (física ou econômica) graças ao efeito específico de mobilização, que só se exerce se for reconhecido, quer dizer, ignorado como arbitrário." ${ }^{13}$ Sem dúvida, as condições sob as quais a grande maioria de imigrantes aportou no país, mesmo aqueles que vieram, nas palavras de Trento, com algum pecúlio, dificilmente reagiriam negativamente a uma proposta como essa e, nesse sentido, essa forma de poder se efetivou, na medida em que se estabeleceu, "numa relação determinada - e por meio desta - entre os que exerceram o poder e os que lhe estiveram sujeitos, quer dizer, na própria estrutura do campo em que se produziu e reproduziu." ${ }^{14}$ Desse modo, o próprio fato de ter sido elaborado por um italiano e em idioma italiano já garantiria o exercício de poder.

O Método Facile, enquanto uma proposta italiana de ensino/aprendizado da língua portuguesa no Brasil por imigrantes italianos, está sendo, aqui, entendido como uma estratégia no sentido bourdieuano ${ }^{15}$ do termo, na medida que se constitui em uma ação decorrente das condições históricas nas quais foram postos esses imigrantes no Brasil. Ele é uma estratégia governamental com intuito de facilitar suas vidas nesse país. Do ponto de vista dos imigrantes que fizeram uso desse manual, esse método pode ser entendido sob o mesmo ângulo de visão. Sem perder de vista o fato de que fizeram uso dele apenas aqueles imigrantes italianos que dominavam a leitura e a escrita, porque dessas

13 BOURDIEU, P. O poder simbólico. Rio de Janeiro: Difel, 1989. p. 14-15.

14 Id.

15 Bourdieu chama de estratégia toda ação que resulta do "habitus que produz práticas individuais e coletivas, produz história, em conformidade com esquemas engendrados pela história”. Cf. BOURDIEU, P. Sociologia. In: ORTIZ, R. (Org.). 1983. p. 76. 
dependeria a utilização do referido método. Por isso, na medida que puderam se apropriar e fazer uso desse recurso visando o aprendizado da língua portuguesa, o método foi utilizado como uma estratégia de convivência social e, conseqüentemente, um instrumento que lhes permitiria maiores possibilidades de relações com o universo de trabalho e, por isso, de sobrevivência em terra estrangeira. Assim sendo, a iniciativa do professor Carlo Del Rosso se achava direcionada a uma parcela reduzida de italianos, já que estes, em sua maioria, eram analfabetos.

\section{Como se apropriar da língua: o guia para estudo}

O autor deixa claro que era importante para o estudante conhecer primeiramente o Guia da obra antes de enveredar por sua leitura. Era chamada de Guia uma introdução na qual estavam inicialmente discriminadas orientações de procedimentos de estudo, bem como a descrição panorâmica do seu conteúdo e de cada uma das partes que eram a origem de sua organização.

Posto isso, convém tratarmos dessas orientações, pois nos permitirão realizar algumas reflexões importantes. Com efeito, o autor esclarece que "a primeira parte do livro é composta de seis exercícios" que devem ser realizados "a cada dois dias. No primeiro dia fará uma leitura em voz alta e a tradução em italiano. No segundo, a tradução do italiano em português, retendo-se na memória as palavras". Para essa etapa, o estudante deveria dedicar doze dias no total. ${ }^{16}$ Os exercícios estavam organizados do seguinte modo:

Pãe nosso que estais no ceo, santificado seja o teu nome. Pái nóssu che estáis nu séu, santificàdu ségia u téu nómi. Padre nostro che stai nel cielo, santificato sai il tuo nome. ${ }^{17}$

16 DEL ROSSO, op. cit., p. 11.

17 Ibid., p. 16, Exercício I. Todos os seis exercícios que compõem a primeira parte seguem esse estilo de organização. 
Devemos notar que as orientações eram bem gerais, considerando aquilo que efetivamente o exercício propunha, que era, o que tudo indica, promover o conhecimento da língua portuguesa, primeiramente, por meio da grafia correta de uma frase, seguida da grafia da pronúncia da mesma frase e, por fim, sua tradução para a língua italiana.

É preciso lembrar que, sob o título IMPORTANTE, o autor advertia: "seja na primeira, na terceira ou na quarta parte, a mensagem segue sempre ao lado da palavra portuguesa e a correspondente pronúncia figurada, para que o imigrante possa com essa guiar-se pela língua falada sem necessitar de ajuda do mestre." 18

Embora, como já frisamos, o Método Facile não contenha princípios pedagógicos explícitos, os procedimentos de orientação de estudo baseados, fundamentalmente, na memorização pela repetição a partir da percepção, permitem-nos dizer que contém elementos de orientação de bases cientificistas naquilo que comporta a caracterização do método intuitivo, cujos precursores, na pedagogia, são Comenius e Pestalozzi. ${ }^{19}$

Essencialmente, o caráter intuitivo baseia-se, na apresentação e observação dos objetos e, na falta destes, das imagens correspondentes. A intuição contribui para o conhecimento, como não pode fazê-lo a descrição verbal [...]. Mas, para que a intuição tenha êxito, não basta apresentar o objeto ou sua imagem isoladamente, devem ser apresentados em relação a um tema determinado e em seu ambiente natural... ${ }^{20}$

A proposta de relação com o conhecimento através do Médoto Facile ocorre a partir de situações com as quais o imigrante se depararia no Brasil. Portanto, ele estaria aprendendo a língua portuguesa em contato direto com a

18 DEL ROSSO, op cit., p. 12.

19 "A intuição não consiste na simples recepção passiva das impressões ou sensações do exterior, mas supõe também participação ativa da vida anímica do paciente. A intuição parte com efeito da visão ou percepção direta de algo presente, coisa ou imagem, e termina com a elaboração conceitual. O conhecimento intuitivo opõe-se ao discursivo tal como se realiza no juízo ou no conceito; mas deve servir de base a estes". LUZURIAGA, L. Pedagogia. São Paulo: Nacional, 1969. p. 233.

20 Ibid., p. 233-234.

21 No método intuitivo, "em qualquer ramo, o ensino deve começar por elementos mais simples e proceder gradualmente de acordo com o desenvolvimento do sujeito..." Cf. MONROE, P. História da Educação. São Paulo: Nacional, 1968. p. 288. 
sociedade onde a língua em questão era falada. Outro aspecto importante é o que diz respeito à complexidade. ${ }^{21} \mathrm{O}$ Método parte de uma orientação de aprendizagem inicialmente com frases simples, por meio do Pai Nosso, avançando para questões gramaticais, sempre com referência à vida do imigrante. Há que ser considerado, também, o tempo a ser reservado para o processo de aprendizagem, sendo conveniente situá-lo na abordagem do método intuitivo. Nesse aspecto, "tempo suficiente deve ser consagrado a cada ponto do ensino, a fim de assegurar o domínio completo dele pelo aluno." 22 Para o estudo da primeira parte, deveriam ser dedicados doze dias. Assim, parece-nos que o desafio para o imigrante estaria em equilibrar o tempo de estudo com o que teria que dedicar ao trabalho.

A seguir, orienta o estudante/imigrante a prosseguir do mesmo modo na segunda parte, à qual devem ser dedicados quatorze dias. No conjunto dessa orientação, o autor assim se dirige ao imigrante: "recomendo ao imigrante o diálogo XII e, especialmente, a anotação sobre Precisa-se (emprego vago)."23 Rosso refere-se ao seguinte exercício:

Eu pressísu de uma criáda che saiba trabagliár Mi ocorri una domestica che suppia lavorare a aglúglia, penteár, lavár, limpár ús vestídús e cod'ago pettinare, lavare, pulire gli abiti e cu signár. - Eu póssu servíla cómu deségia, porché séi cinare. - Io posso servila come desidera, perche so tambén contár. - Quantú témpu e che serve? - Dóis anche contare. $-[\ldots]^{24}$

Devemos observar que o diálogo anuncia uma situação com a qual o imigrante poderia se deparar ao conversar com um interessado em contratar serviços domésticos. Notemos que se acha grafado da maneira como se pronuncia em português, seguido de tradução para o italiano.

Mais adiante, acrescenta que "concluído o estudo da terceira parte, certamente o estudante será capaz de ler o jornal, compreender e transcrever qualquer frase simples..." ${ }^{25}$ Ora, se as duas primeiras partes permitiriam ao

22 MONROE, op. cit., p. 288.

23 DEL ROSSO, op. cit.

24 Ibid., p. 59. Transcrição do original na íntegra.

25 Id. 
imigrante italiano compreender e se exprimir inteligentemente em língua portuguesa, o aprendizado adquirido por meio delas, bastaria para ler, compreender e escrever frases simples. Então, é pressuposta a idéia de que não precisaria da terceira parte para tal. Esta, por se referir a aspectos estritamente gramaticais, serviria para o aperfeiçoamento da escrita e da fala, já que se trata de uma "sucinta gramática prática e de fonética da língua portuguesa." ${ }^{26}$ Aliás, o treino da pronúncia em língua portuguesa é uma preocupação que se estende até a quinta parte do método, mesmo porque a natureza das informações constantes a partir daí não mais o exige. ${ }^{27}$ Vejamos alguns exemplos dessa parte: " $\mathrm{Ce}, \mathrm{Ci}$, pronunciasi se, si; p. es.: MEDICINA, pronunciasi medisina; Ç colla cediglia, pron. come s duro; p. es.: FRANÇA, pron. Fránsa."

Rosso reitera que "o estudioso deve praticar com zelo, a fim de reter na memória. Deve ainda procurar copiar muitas vezes para que possa transcrever com segurança e sem erro. A tal ponto que, ao ditar a um amigo, escrevendo as palavras como se pronunciam em português, bastaria ler como se fosse em italiano." Para ele, "este é um exercício utilíssimo de se fazer, concomitantemente com a subseqüente pequena gramática." 28 (grifos nossos). Essas orientações se resumiam em exigências a serem seguidas pelo estudante.

Esses dados nos permitem pensar nas condições concretas sob as quais se achava o imigrante em solo brasileiro. Principalmente, se considerarmos que este deveria dedicar, e sem sombra de dúvida dedicou, a maior parte de seu tempo ao trabalho. Em contrapartida, é contraditório imaginar que tais exigências pudessem esbarrar abruptamente com a luta pela sobrevivência por parte do italiano no Brasil. Corroboramos essa afirmação com Petrone, quando se refere à importância não atribuída à escola por imigrantes italianos e que soa perfeitamente cabível aqui:

26 A terceira parte é a mais longa por ser composta de vinte e seis capítulos sobre abordagem da gramática portuguesa.

27 A sexta parte trata da lei aprovada pelo ministro Francisco Glicério, que regula a imigração no Brasil; a sétima, da moeda utilizada no Brasil; a oitava trata das companhias de navegação que transportam imigrantes para o Brasil; a nona demonstra o regulamento brasileiro, quando ao recebimento, abrigo e destino do imigrante; a décima e última parte faz uma descrição geral do Brasil e de seus Estados em particular.

28 DEL ROSSO, op. cit., p. 82-83. 
[...] mais vale a prática do que a gramática. Esse na verdade pode ser considerado o lema que norteou o comportamento de uma parte considerável de imigrantes. Eles não podiam perder tempo. Era necessário trabalhar duro para que o sonho de fazer a América pudesse tornar-se realidade. Isso foi válido quer para os colonos das fazendas de café, quer para os habitantes das colônias do sul e núcleos coloniais do sudeste, quer para aqueles que se instalaram nos centros urbanos ${ }^{29}$ [grifos nossos].

Vimos então que as orientações postas no guia esbarram na problemática do tempo, proporcionada pela necessidade premente que os imigrantes italianos tinham de trabalhar.

\section{Religião e trabalho}

Algumas passagens do método serão analisadas, neste item, considerando o conteúdo nelas existente. Para tanto, faremos uso apenas da primeira e da terceira parte, já que as situações aí descritas servem de modelo para metade do manual.

Com efeito, a religião faz, juntamente com o trabalho, uma espécie de duo, a partir do qual se intenta incutir no imigrante uma série de condutas e comportamentos que visam o cultivo de uma postura dócil, conformada e fundamentalmente subserviente.

Uma passagem da oração "Pai Nosso" possibilita algumas considerações, vejamos:

29 PETRONE, P. Italianos descendentes do Brasil: escola e língua. In: BONE, L. A. (Org.). Prenseça italiana no Brasil. Porto Alegre: Escola Superior de Teologia, 1990. v. 2. p. 603-604.

30 DEL ROSSO, op. cit., p. 16-17, Exercício I. Transcrição do original na íntegra. 
Que o nosso pãe seja santificado.

Che u nóssu pái ségia santificado.

Che il nostro padre sai santificado.

Que o nome de Deos nosso pae seja sanctificado. Que nome tem teu pãe? João. E tua mãe?

Che u nómi de Déus nóssu pái ségia sanctificado. Che nómi tén téu pái? Joàn. E túa mái?

Che il nome di Dio nostro padre sai santificato. Che nome há tuo padre? Giovanni. E tua madre?

A última estrofe, na sequiência da transcrita acima, foi elaborada visando iniciar uma conversa entre um imigrante e um fazendeiro:

[imigrante] Eu venho pedir-lhe este favor porque meu irmão, en vez de vir elle comigo, elle veio so acompanhar-me até além da ponte que está sobre o rio dizendo que virá aquí a tomar-me hoje o amanhã. [fazendeiro] É melhor que elle venha amanhã, pois assim podereis parar aqui e jantar conosco.[imigrante] Vossa excellencia é sempre tão cortez! [fazendeiro] Acceitais então? [imigrante] Muitas graças. Vossa excellencia, muitas vezes nos favorece e também hontem quis convidar meu pai que veio a sua casa. [fazendeiro] Não vale a pena falar nisso. [imigrante] Breve viremos todos a trabalhar na sua fazenda; pode ser que no mez proximo depois de... [fazendeiro] Quanto quereis de soldo? [imigrante] Que tipo de trabalho é? [fazendeiro] Qual é o que preferis??31

Com efeito, duas compreensões importantes podem ser depreendidas desse diálogo. A primeira delas se refere à solicitude tanto por parte do fazendeiro quanto do imigrante. Daquele, principalmente ao convidar o italiano para jantar, chegando ao ponto de inquirir-lhe sobre o tipo de trabalho de sua preferência e, mais ainda, quanto desejaria ganhar. Do italiano que, agradecido, reconhece a extrema gentileza do candidato a patrão. A despeito disso, a historiografia sobre imigração italiana tem mostrado que, genericamente

31 DEL ROSSO, op. cit., p. 20-23. Transcrição do original na íntegra, em que a grafia dos diálogos não foi feita antecedida de travessão. 
falando, as relações entre essas duas esferas nunca foram tão pacíficas assim. $\mathrm{O}$ imigrante tinha que se submeter às condições de trabalho impostas pelo fazendeiro. Raríssimas eram as situações em que essas relações não foram mais do que uma mera extensão daquelas estabelecidas entre senhor e escravo. ${ }^{32}$ Habituado a comandar os escravos, o proprietário fundiário não abdicava de sua mentalidade e só depois de muitos anos começou a fazer algumas concessões no plano da disciplina e dos métodos para mantê-la. ${ }^{33}$

O trecho abaixo é ponto de partida para a divulgação de uma mensagem que vincula Deus ao trabalho e cuja vontade deve ser satisfeita:

Seja feita a vossa vontade assim no ceo como na terra.

Ségia féita a vóssa vontádi assim nu séu còmu na terra.

Sia fatta la vostra volontà cosi nel cielo come sulla terra. ${ }^{34}$

Na seqüência, temos:

eu quero que a tua vontade seja feita em todo quanto tu queres (quizeres). Si elle não quiser fazer o que tu queres, sem cerimônias tu podes dizer que não o queremos conosco. Elle não tem vontade de fazer este trabalho. Por que estas pessoas não querem trabalhar? Por que ellas não tem o tempo. Eu quizera vir contigo, porém não posso. Quando puder virei e iremos na igreja a rogar o bom Deos que do ceo nos ajude e nos envie bons conselhos. Abençoado seja Deos nosso senhor! Um bom cristão é muito mais honesto e trabalhador do que, não tendo religião nenhuma nem princípios $[\ldots]^{35}$ [grifos nossos].

Nessa esteira, segue a idéia de que o orador tudo recebe de Deus, fundamentalmente a comida:

32 Cf. ALVIM, Z. M. O Brasil italiano (1880-1920). São Paulo: Edusp, 1999; HALL, M. Imigrantes. Trabalhadores, Campinas, 1989; HOLLOWAY, op. cit.

33 TRENTO, A. Do outro lado do Atlântico: um século de imigração italiana no Brasil. São Paulo: Nobel, 1989. p. 48.

34 DEL ROSSO, op. cit, p. 23, Exercício III. Transcrição do original na íntegra.

35 Ibid., p. 24-27, Exercício III. Transcrição do original na íntegra. 
O pão nosso de cada dia dai-nos hoje

U páon nóssu de cáda día dái nus óge.

Il pane nostro di ogni giorno date a noi oggi. ${ }^{36}$

Ao mesmo tempo em que recebe de Deus o pão, ou seja, a comida, também deve doar e assim demonstrar amor por Ele: a estrofe acima é portadora dessa concepção, da qual seguem os diálogos: "que nos dará para jantar? Lhes darei um pedaço de carne cocida, uma tigela de caldo, um copo de vinho. Daí a esmola aos pobres. Quem não faz esmola aos pobres não ama a Deos. Deos nos da o nosso pão de cada dia. [...]. Cada dia ricas senhoras brasileiras dão pão a estes pobres rapazes emigrantes." ${ }^{37}$

Observe que, nessa passagem, outra merece ser comentada: as ricas senhoras brasileiras que fazem caridade, doando comida ao imigrante, são exemplo a ser seguido. Significa dizer que Deus deu a elas o pão, a riqueza e por isso demonstram amá-Lo e, por que não dizer, temê-Lo. O Deus que dá o pão, também deve ampará-lo em terra estranha:

Não nos deixai cahir em tentação, mas livrai-

E non nus deisciái cair en tentassón, mas livrái-

E non ci lasciate cadere in tentazione, ma libera-

nos do mal. Amem.

nus do mal. Amen.

teci dal male. Amen. ${ }^{38}$

Ampará-lo a fim de que não enverede por caminhos tortuosos, por isso: "não deixai-nos cahir na tentação de não ir à igreja todos os domingos. Eu quero sempre ser um bom moço, religioso, obediente, trabalhador." ${ }^{39}$ Pelo amparo, pela proteção de Deus, teria a contrapartida da obediência, da bondade,

36 DEL ROSSO, op. cit., p. 27, Exercício IV. Transcrição do original na íntegra.

37 Ibid., p. 27-32, Exercício IV. Transcrição do original na íntegra.

38 DEL ROSSO, op. cit., Exercício VI. Transcrição do original na íntegra.

39 Ibid, p. 38. 
da veneração e, acima de tudo, do trabalho. Este que seria fonte de propriedade e, portanto, de ascensão social. No trecho a seguir, há a tentativa de incutir, no jovem imigrante de dezesseis anos, a ideologia da propriedade em solo brasileiro: "quando eu vim para o Brasil eu era um menino, mas agora sou um moço e tenho dezesseis anos. Breve serei um homem; terei o meu lote de terreno como teve meu pae. - Serei agricultor e cultivarei o solo com meu irmão. - Irei para o Rio comprar instrumentos agrícolas..." ${ }^{40}$ Concretamente falando, essa era uma condição muito difícil de ser alcançada pelo imigrante. TRENTO (1989) assinala que os imigrantes, ao chegarem nas fazendas de café, eram informados por seus compatriotas de que, além de terem que cuidar de 4,5 mil pés de café, os salários eram, muitas vezes, inferiores aos anunciados. ${ }^{41}$ Outrossim, mesmo que conseguissem algum dinheiro, dificilmente este lhes sobraria, pois tinham que retorná-lo ao fazendeiro como parte do pagamento de compras de gêneros de que necessitavam e que eram aí adquiridos, na maioria das vezes, por preços exorbitantes. Por conseguinte, não seria demais nos referir a esta passagem de HALL, citado por TRENTO (1989, p. 49):

[...] a impossibilidade, de parte dos imigrantes, de obter proteção legal contra os fazendeiros foi um importante fator nesse sentido, além da violência física. Isso significava, por exemplo, que o fazendeiro era livre de praticar uma série de abusos econômicos contra seus trabalhadores. Os métodos variavam conforme a amplitude da oferta do momento e outros fatores, mas o objetivo era apropriar-se de todo o excedente criado pelos colonos. Entre os expedientes utilizados, havia as multas, os armazéns das fazendas, o confisco de produtos, a adulteração de pesos e medidas e a retenção de salários. ${ }^{42}$

Dessas relações, decorreriam inúmeros conflitos entre fazendeiros e imigrantes. Porém, constatamos que o método não deixa de trazer implícita a ideologia da prosperidade, a ser incutida no imigrante por parte da Sociedade Promotora da Imigração. Com sua criação, em 1886, essa sociedade foi

40 DEL ROSSO, op. cit., p. 38-39, Exercício VI.

41 Cf. TRENTO, op. cit., p. 47.

42 HALL, M. The origins of mass immigration in Brazil, 1871-1914. p. 128. 
organizada com o intuito de "recrutar, transportar e distribuir mão-de-obra imigrante." ${ }^{\prime 3}$ Além disso, visava melhorar a publicidade negativa do Brasil, que vinha sendo feita durante anos e que se constituía num obstáculo para a imigração européia. Tal publicidade foi feita principalmente por italianos que fizeram críticas à vida em São Paulo. Diante disso, o governo italiano, em 1885, distribui uma circular, caracterizando-a como uma cidade inóspita e insalubre e recomendando que se evitasse a imigração para o Brasil. ${ }^{44}$

Segundo HOLLOWAY (1984), assim que essa sociedade foi criada, os seus diretores "iniciaram imediatamente suas atividades promocionais". Destacando ainda que:

Uma das primeiras realizações foi a publicação de uma brochura, pormenorizando as atrações de São Paulo. O folheto, com sessenta páginas, foi publicado por subvenção do Ministério da Agricultura do Império, ocupado na ocasião por Antônio da Silva Prado, irmão de Martinho. Tinha uma capa de colorido brilhante para chamar a atenção e um grande mapa de São Paulo nas páginas finais. Oitenta mil cópias foram impressas em português, alemão e italiano. $\mathrm{O}$ texto, sempre que possível, fazia comparações favoráveis com a Argentina, Estados Unidos e países europeus. Não havia menção a problemas raciais ou à existência, ainda, da escravidão. Mas se assinalava cuidadosamente que em São Paulo "a maneira de vestir, mobiliar as casas, alimentar-se e, em geral, todos os costumes são europeus." O folheto arrolava as facilidades à disposição das famílias imigrantes: transporte do Rio de Janeiro ou Santos para a cidade de São Paulo, comida para até oito dias e alojamento na hospedaria, incluindo tratamento médico gratuito e transporte ferroviário igualmente gratuito para destinação final no interior da província.... ${ }^{45}$

Constatamos, então, que o Método Facile, diante das características do manual descrito acima, representava um outro meio de propaganda feito por iniciativa daquela sociedade, apenas com duas diferenças básicas: ensinar a língua portuguesa e, ao mesmo tempo, divulgar, através da dimensão das relações sociais, a imagem de um país sem conflitos sociais, cujas pessoas eram bondosas e sumamente educadas.

43 HOLLOWAY, op. cit., p. 64.

44 Id.

45 Ibid. p. 65. 
Atitudes de civilidade também são incutidas através de diálogos que o imigrante residente, tanto na cidade do Rio de Janeiro como na de São Paulo, poderia travar com a pessoa que o atendesse, quer fosse, por exemplo, em termos de hospedagem, nos correios e telégrafos, quer procurando trabalho e quarto para dormir, comprando móveis, indo ao médico, queixando-se de doença, comprando tecidos em uma loja, chegando a um alfaiate, comprando livros na livraria, ${ }^{46}$ enfim, onde quer que ele imaginasse ir.

Devemos ressaltar que o capítulo é rico em expressões que o estimulam a se dirigir a uma pessoa com urbanidade: "O senhor me enche de favores. Não sei como corresponder! Esta é uma prova de amizade. Peço-lhe que me dispense. Não é possível. Desejo ser-lhe útil. Conto com seu reconhecimento. Seu humilde criado". ${ }^{47}$

A indução à civilidade pode ser explicada através de dois aspectos: o da necessidade de disciplinarização do imigrante nos espaços urbano e rural, nas relações sociais, assim como submetê-lo mais facilmente a relações de mando e subserviência. Isso se devia, de um lado, à concepção de que o imigrante, especialmente o italiano, era indisciplinado. De outro, à mentalidade escravocrata, que era comum aos segmentos dirigentes, especialmente aquele responsável pelas iniciativas imigrantistas, dos quais a Sociedade Promotora de Imigração era uma representante.

Sob esse olhar, a apropriação da língua se manifesta como um mecanismo que poderia ser mais eficaz no sentido de não só cooptar o imigrante para o convívio numa sociedade cortês, mas também controlá-lo e discipliná-lo nas relações sociais. Podemos entendê-la ainda, como uma iniciativa de segmentos republicanos, visando, antes de tudo, divulgar a imagem de uma sociedade brasileira educada, polida e hospitaleira. $\mathrm{O}$ trecho abaixo ilustra bem isso:

As estalagens são boas e baratas.

Quer o senhor tomar alguma coisa?

Venha comigo em uma hospedaria a qual não está longe daqui.

De que lado é?

O senhor faz-se muito favor em indicar-me uma estalagem onde eu possa encontrar um bom almoço.

Vá na Rua Sete de Setembro ai há muitas e baratas.

Tenha o senhor a bondade de indicar onde está a rua.

46 Cf. DEL ROSSO, op. cit., p. 54-77.

47 Ibid., p. 83-84, capítulo I. 
Ela está perto do porto, do Largo do Paço.

Eu desejo comer um prato de carne, uma sopa e um queijo.

Dá-me um copo de vinho, uma garrafa.

Se me dá licença, eu vou à adega tomar uma garrafa do melhor vinho que tenho. ${ }^{48}$

A explicação para isso se encontra no fato de que a imagem do Brasil, na Europa, estava maculada devido ao tratamento que vinha sendo dado ao imigrante. As propagandas negativas, que há muito vinham sendo feitas, já se constituíam, segundo HOLLOWAY (1984), num sério obstáculo ao empreendimento de novas políticas imigrantistas. ${ }^{49}$ Por esse motivo, foi preciso construir uma outra imagem de relação e de tratamento para o imigrante no Brasil.

\section{REFERÊNCIAS}

ALVIM, Z. M. O Brasil italiano (1880 - 1920). São Paulo: Edusp, 1999.

BRANDÃO, C. R. O que é Educação. São Paulo: Brasiliense, 1986.

BOURDIEU, P. O poder simbólico. Rio de Janeiro: Difel, 1989.

BOURDIEU, P. Sociologia. In: ORTIZ, R. (Org.). 1983.

DEL ROSSO, C. Método Facile: teórico-pratico per imparare senza maestro la língua portoghese. Manuale indispensabile per l'emigrante che si al Brasile. Bueno Aires: Casa Editriche A. Bietti, 1892.

DIÁRIO de Campinas, 1887 e 1888, Arquivo Edgard Leuenroth, Universidade Estadual de Campinas.

HALL, M. Imigrantes. Trabalhadores, Campinas, 1989.

48 DEL ROSSO, op. cit., p. 85-86, capítulo III. Este diálogo, no original, não está grafado com travessão no seu início.

49 Cf. HOLLOWAY, op. cit., p. 64. 
CORRÊA, R. L. T. Urbanidade e disciplinarização...

HOLLOWAY, T. H. Imigrantes para o café: café sociedade em São Paulo 1886-1934. São Paulo: Paz e Terra,1984.

LUZURIAGA, L. Pedagogia. Tradução de: Lólio Lourenço de Oliveira. São Paulo: Nacional, 1969.

MONROE, P. História da Educação. São Paulo: Nacional, 1968.

PETRONE, P. Italianos descendentes do Brasil: escola e língua.In: BONE, L. A. (Org.). Presença italiana no Brasil. Porto Alegre: Escola Superior de Teologia: 1990. v. 2.

TRENTO, A. Do outro lado do Atlântico: um século de imigração italiana no Brasil. São Paulo: Nobel, 1989. 